\title{
Promoter methylation of the bone morphogenetic protein 6 gene in multiple myeloma
}

\author{
YUMIKO HASHIDA $^{1}$, YUIKO NEMOTO ${ }^{1}$, MASAYUKI IMAJOH ${ }^{1}$, MASANAO MURAKAMI $^{1}$, \\ AYUKO TANIGUCHI $^{2}$, NAOKI KOMATSU ${ }^{3}$, AKIHITO YOKOYAMA ${ }^{2}$ and MASANORI DAIBATA ${ }^{1}$ \\ Departments of ${ }^{1}$ Microbiology and Infection, ${ }^{2}$ Hematology and Respiratory Medicine, and \\ ${ }^{3}$ General Medicine, Kochi Medical School, Kochi University, Kochi, Japan
}

Received September 19, 2011; Accepted October 25, 2011

DOI: $10.3892 / o r .2011 .1548$

\begin{abstract}
Bone morphogenetic proteins (BMPs), which belong to the transforming growth factor- $\beta$ superfamily, are multifunctional signaling molecules that have become of increasing interest in cancer research. Recent observations suggest that alterations in BMPs and BMP signaling are associated with tumorigenesis and disease progression in various types of malignancies. This study investigated the methylation status of the BMP6 gene promoter in various types of plasma cell proliferative disorders by combined bisulfite restriction analysis. While BMP6 methylation was not detected in any samples from monoclonal gammopathies of undetermined significance, intramedullary multiple myeloma (MM), plasma cell leukemia or solitary plasmacytoma, both case studies and cell line studies showed that multiple extramedullary plasmacytoma (MEP) consistently carried a methylated BMP6 promoter. The BMP6 methylation-positive MEP was an aggressive form of MM with extremely high levels of serum lactate dehydrogenase (LDH). Bisulfite sequencing analysis confirmed intensive methylation at $\mathrm{CpG}$ sites of the $B M P 6$ promoter region. The methylation of $B M P 6$ was correlated with decreased levels of mRNA transcripts. Expression of BMP6 was restored by the demethylating agent 5-aza-2'-deoxycytidine, suggesting that the methylation is associated with transcriptional silencing. Our study implied that BMP6 promoter methylation is not a common event in MMs, but occurs in aggressive MEP. These findings warrant further investigation to clarify whether BMP6 methylation together with elevated LDH could be a marker of poor prognosis in MEP patients who should be considered for early intensive treatment.
\end{abstract}

Correspondence to: Dr Masanori Daibata, Department of Microbiology and Infection, Kochi Medical School, Kochi University, Kochi 783-8505, Japan

E-mail: daibatam@kochi-u.ac.jp

Key words: multiple myeloma, plasmacytoma, BMP6, methylation

\section{Introduction}

Multiple myeloma (MM) is a clonal malignancy of plasma cells that develops as a consequence of a multistep transformation process. MM is thought to evolve most commonly from a monoclonal gammopathy of undetermined significance (MGUS) that progresses to smoldering MM and, eventually, to symptomatic MM after development of several genetic abnormalities (1). Additional genetic and biological factors related to the proliferative activity of the malignant plasma cells, angiogenesis and bone metabolism may transform the myeloma clone further to more aggressive disease states known as plasma cell leukemia (PCL) and multiple extramedullary plasmacytoma (MEP), in which the clonal cells lose their dependency on the bone marrow microenvironment (2).

Genetic abnormalities in a large number of genes have been described in MM. Important genetic changes for the pathogenesis of MM include translocations involving the immunoglobulin heavy chain locus on chromosome 14q32, which result in transcriptional activation of $M A F, M M S E T$, $C C N D 1, C C N D 3$ or $M A F B$, and numerous structural and copy number alterations $(1,3,4)$. Late-onset translocations and gene mutations that are implicated in disease progression include complex karyotypic abnormalities in $M Y C$, the activation of NRAS and KRAS, mutations in TP53, and inactivation of $C D K N 2 A$ and $C D K N 2 C(1,3,4)$. Thus, the genetic abnormalities associated with the origin and progression of MM are becoming more apparent, but the role of epigenetic modifications is still poorly understood.

Aberrant methylation of promoter DNA regions rich in $\mathrm{CpG}$ islands has been recognized as a major mechanism of epigenetic gene silencing. To date, promoter methylation in MM has been reported in several studies, mainly focusing on the methylation status of genes encoding proteins with functions in cell growth control and apoptosis (5-7). Identification of novel genes whose expression in MM is regulated by methylation is of great importance for better understanding of the pathogenesis and prognostic implications of the disease.

Bone morphogenetic proteins (BMPs), members of the transforming growth factor- $\beta$ (TGF- $\beta$ ) superfamily, were originally identified as molecules involved in the regulation of osteogenic differentiation, but are now appreciated to have critical functions in a wide range of developmental processes 
$(8,9)$. Dysregulation of BMPs and BMP signaling is also implicated in disease states, including cancers. For example, activation of BMP signaling inhibits some cancer types, such as colorectal cancer, by promoting growth arrest and differentiation and by inducing senescence (10). In addition, loss of BMP expression was reported in association with development and progression of cancers of the colon, stomach, prostate, and lungs (11-16), and recent studies reported that BMP2, BMP4, BMP5, BMP6, and BMP7 inhibit proliferation and induce apoptosis of myeloma cells (17-21). Although these findings may define the role of BMPs as tumor suppressors, the underlying mechanism of the effects of BMPs in tumorigenesis has not been well delineated.

Of the genes for these BMPs, BMP6 became the focus of our interest in studying methylation-dependent gene regulation in $\mathrm{MM}$, as it was shown that BMP6 expression is suppressed in actively proliferating myeloma cells or plasmablasts (21), and since the BMP6 promoter region is abundant in $\mathrm{CpG}$ islands that are susceptible to methylation (22). Furthermore, we recently showed that $B M P 6$ promoter methylation and its resultant loss of BMP6 expression were found in aggressive types of malignant lymphomas and leukemias $(23,24)$. Thus, we hypothesized that the $B M P 6$ promoter may be methylated in more aggressive types of $\mathrm{MM}$, and that the loss of $B M P 6$ expression may contribute to the pathogenesis and progression of aggressive MM.

\section{Materials and methods}

Samples. Bone marrow aspirates, leukemic peripheral blood, or biopsied tissues were obtained from 27 pretreated MM patients (12 men and 15 women with a median age of 67 years at diagnosis; range, 37-87 years) and included samples of intramedullary MM, extramedullary MM (plasmacytomas) and PCL. Based on the Durie-Salmon classification, the study population was divided into $37 \%$ stage I (10 cases, denoted as cases I-1 to I-10), 26\% stage II (seven cases, II-1 to II-7) and $37 \%$ stage III (10 cases, III-1 to III-10). Three samples were from biopsied plasmacytomas (cases II-4, II-5 and II-6). The stage III group included 3 PCLs (cases III-2, III-9 and III-11) with plasma cell counts of $2.1-11.9 \times 10^{9} / 1$ in peripheral blood. Five relapsed cases were also studied. In addition, three cases of MGUS were enrolled in this study (patient median age 76 years; range, 74-78 years). Five MM cell lines (U-266, delta-47, Maska-98, Flam-76 and Fuji-6) were also subjected to methylation analysis. This study received the approval of the Ethics Committee of Kochi Medical School, Kochi University.

Methylation analysis. Sodium bisulfite modification of isolated genomic DNA ( $1 \mu \mathrm{g})$ was performed using the EpiTect Bisulfite kit according to the manufacturer's instructions (Qiagen, Valencia, CA, USA). Aliquots of the bisulfitetreated DNA were amplified by polymerase chain reaction (PCR) in reaction mixtures containing $67 \mathrm{mM}$ Tris- $\mathrm{HCl}$ ( $\mathrm{pH}$ 8.8), $16.6 \mathrm{mM}\left(\mathrm{NH}_{4}\right)_{2} \mathrm{SO}_{4}, 6.7 \mathrm{mM} \mathrm{MgCl}{ }_{2}, 10 \mathrm{mM}$ $\beta$-mercaptoethanol, $1.25 \mathrm{mM}$ each deoxynucleotide triphosphate mixture, $0.5 \mathrm{mM}$ of each primer, and $1 \mathrm{U}$ of Ex Taq Hot Start Version polymerase (Takara, Shiga, Japan). The primers were 5'-GGGGTAAATTTTATGGTGGTT-3' (sense primer) and 5'-CCTCAATCCTTATCTCTCATA-3' (antisense primer), which give a PCR product of 387 base pairs (bp), encompassing the BMP6 promoter region -521 to $-134 \mathrm{bp}$ relative to the transcriptional start site. The PCR conditions were $3 \mathrm{~min}$ at $94^{\circ} \mathrm{C}$ followed by 35 cycles of $94^{\circ} \mathrm{C}$ for $40 \mathrm{sec}$, $56^{\circ} \mathrm{C}$ for $30 \mathrm{sec}$, and $72^{\circ} \mathrm{C}$ for $30 \mathrm{sec}$. Combined bisulfite restriction analysis (COBRA) was carried out by overnight digestion of the PCR products at $60^{\circ} \mathrm{C}$ with a restriction enzyme BstUI (New England BioLabs, Ipswich, MA, USA) which has the recognition sequence 5'-CGCG-3'. The digested fragments correspond to methylated DNA (25). The resultant DNA fragments were electrophoresed on $2.5 \%$ agarose gels and visualized by ethidium bromide staining under ultraviolet (UV) light.

In these analyses, two lymphoma cell lines, Akata (Burkitt's lymphoma cell line) and SP-53 (mantle cell lymphoma cell line), were employed in parallel as BMP6 methylation-positive and -negative controls, respectively. The BMP6 promoter of Akata cells has previously been shown to be fully methylated, while the promoter in SP-53 cells show no evidence of methylation (23).

Bisulfite genomic sequencing. The PCR products were purified with the High Pure PCR Production Purification kit (Roche Diagnostics, Tokyo, Japan). The purified PCR products were cloned into the pMD20-T vector, and transformed into the Escherichia coli strain JM109 with the Mighty TA Cloning kit (Takara). Five to six clones for each myeloma sample were selected by blue-white color screening, and sequenced with the M13 primer RV or M13 primer M4 (Takara). The DNA sequence was determined with an ABI-310 sequencer using the BigDye terminators version.1.1 (Applied Biosystems, Foster City, CA, USA).

Reverse-transcription (RT)-PCR. Total RNA was isolated using TRIZol reagent (Invitrogen, Carlsbad, CA, USA). Before $\mathrm{RT}$, a total of $1 \mu \mathrm{g}$ of RNA was treated with DNase I (Invitrogen) to remove any DNA contaminant. The DNase I-treated RNA was subjected to RT with ThermoScript reverse transcriptase (Invitrogen). The cDNA samples (equivalent to the cDNA amount from $50 \mathrm{ng}$ of initial total RNA) were PCR-amplified, and the products were electrophoresed on $2.0 \%$ agarose gels followed by ethidium bromide staining and visualization under UV light for the presence of DNA bands of appropriate sizes. The sequences of the primers used to amplify the BMP6 gene were 5'-CGACAACAGAGTCGTAATCG-3' and 5'-GCATTCTCCATCACAGTAATTG-3', yielding a 195-bp fragment. As a control for cDNA integrity and PCR reactions, the gene encoding $\beta$-actin was amplified in parallel using the following primers: 5'-ACCTTCAACACCCCAGCCATG-3' and 5'-GGCCATCTCTTGCTCGAAGTC-3', giving a 309-bp fragment.

5-Aza-2'deoxycytidine (5-aza-dC) treatment. Cells were grown in RPMI-1640 medium supplemented with $10 \%$ fetal calf serum. For 5-aza-dC experiments, the cells were treated with either $5 \mu \mathrm{M}$ [from $10 \mathrm{mM}$ stock in dimethyl sulfoxide (DMSO)] 5-aza-dC (Sigma, St. Louis, MO, USA) or with vehicle alone (DMSO) for 5 days with fresh medium containing either 5-aza-dC or DMSO being added every $48 \mathrm{~h}$. 


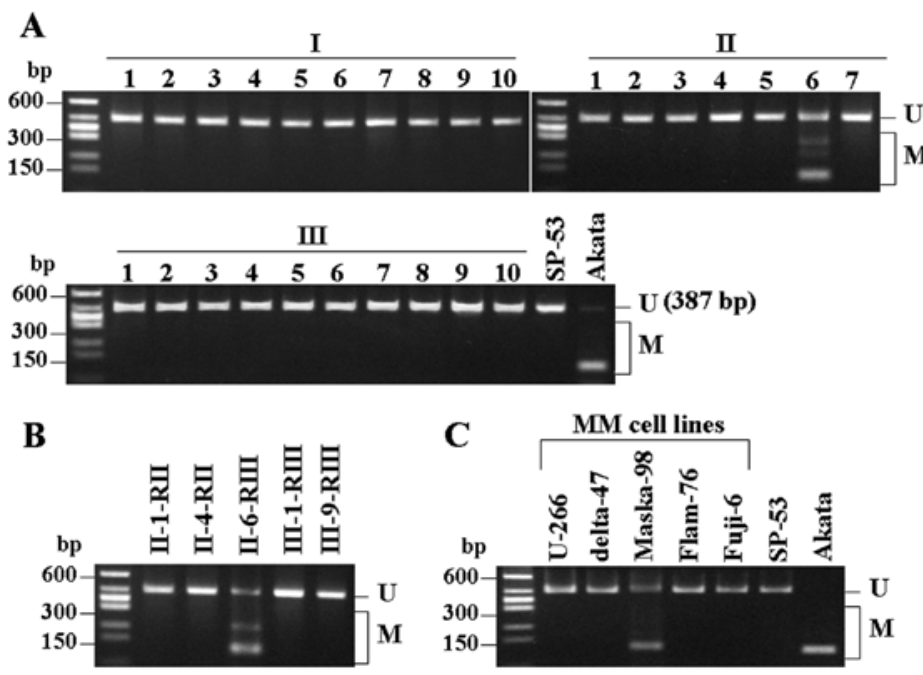

Figure 1. COBRA results for BMP6 promoter methylation in MM cases at diagnosis (A), relapsed MM cases (B), and MM cell lines (C). The PCR products ( $387 \mathrm{bp)} \mathrm{from} \mathrm{bisulfite-treated} \mathrm{DNA} \mathrm{were} \mathrm{digested} \mathrm{with} B s t \mathrm{UI}$, which generated digested bands of various sizes. The digested fragments correspond to methylated DNA. Case numbers are shown on top. The BMP6 promoter of Akata cells was previously shown to be methylated, while SP-53 cells show no evidence of methylation (23). Experiments were conducted in parallel with Akata and SP-53 cells as methylation-positive and -negative controls, respectively. Molecular size marker ( $\phi$ X174/HincII-cut DNA) is shown on the left. U, unmethylated fragment; M, methylated fragment.

After the drug treatment, cells were harvested for DNA and RNA extractions.

\section{Results}

Methylation analysis of the BMP6 promoter. We screened bone marrow aspirates, leukemic peripheral blood, or biopsied specimens of plasmacytomas from pretreated patients with various types of MMs, including intramedullary MMs, extramedullary plasmacytomas and PCLs, for the presence of $B M P 6$ promoter methylation. None of the intramedullary MMs or PCLs had a methylated BMP6 promoter, with the exception of case II-6 (Fig. 1A). Of the three cases of plasmacytoma studied (cases II-4, II-5 and II-6), case II-6 was an MEP having at diagnosis elevated serum levels of lactate dehydrogenase (LDH) six times higher than the upper limit of normal, while the other two cases without BMP6 methylation were solitary plasmacytomas with normal levels of serum LDH. The disease in case II- 6 rapidly progressed to stage III of the Durie-Salmon staging system at relapse (denoted as case II-6-RIII), and methylation of the BMP- 6 promoter was consistently found (Fig. 1B). Sequential case follow-up studies showed that none of the other four relapsed cases (II-1-RII, II-4-RII, III-1-RIII, and III-9-RIII) had BMP6 promoter methylation. We also evaluated the methylation status of bone marrow aspirates from three patients with MGUS, none of which showed detectable BMP6 promoter methylation (data not shown).

To further investigate $B M P 6$ promoter methylation in MM, we conducted COBRA on five MM cell lines: U-266 is from a patient with intramedullary MM; Flam-76 and Fuji-6 from PCL; delta-47 from solitary plasmacytoma; and Maska-98 from MEP (26). As shown in Fig. 1C, methylation of the BMP6 promoter was found only in Maska-98. Maska-98 was derived from a patient with relapsed MEP whose serum LDH level was 30 times higher than the upper limit of normal (27). These results suggested that although $B M P 6$ promoter methylation was not a common event in MM, it appears to occur in MEP.

Bisulfite sequencing analysis. To confirm the methylation at the cleavage sites of the restriction enzyme along with the methylation of other neighboring $\mathrm{CpG}$ sites, four samples, including two from MM patients (cases II-6 and III-8) and two MM cell lines (U-266 and Maska-98), were subjected to bisulfite sequencing. The PCR products were cloned into plasmid vectors and five to six independent clones were sequenced. As shown in Fig. 2, the bisulfite sequencing showed good concordance with the results of COBRA. In samples found to be methylated by COBRA (case II-6 and Maska-98), extensive methylation across the $\mathrm{CpG}$ islands was noted, whereas the samples (case III-8 and U-266) in which methylation could not be detected by COBRA showed no or little methylation at CpG sites of the BMP6 promoter region.

Association of BMP6 promoter methylation with transcriptional gene silencing. To elucidate whether the aberrant methylation of BMP6 is associated with loss of BMP6 expression, we analyzed expression of $B M P 6$ transcripts by RT-PCR with cycle numbers that amplified the $\beta$-actin cDNA to plateau levels. Representative results are shown in Fig. 3A. MM samples with little $B M P 6$ promoter methylation expressed BMP6 mRNA transcripts, whereas samples with $B M P 6$ promoter methylation (for example, cases II-6 and Maska-98) had barely detectable BMP6 mRNAs. These results suggested that the $B M P 6$ promoter methylation correlated with loss of $B M P 6$ expression.

Restoration of BMP6 expression by a demethylation agent . To confirm that the loss of BMP6 expression was due to promoter methylation, Maska-98 cells were incubated in the presence or absence of 5-aza-dC, and the methylation status and BMP6 mRNA expression were analyzed by COBRA and RT-PCR, 


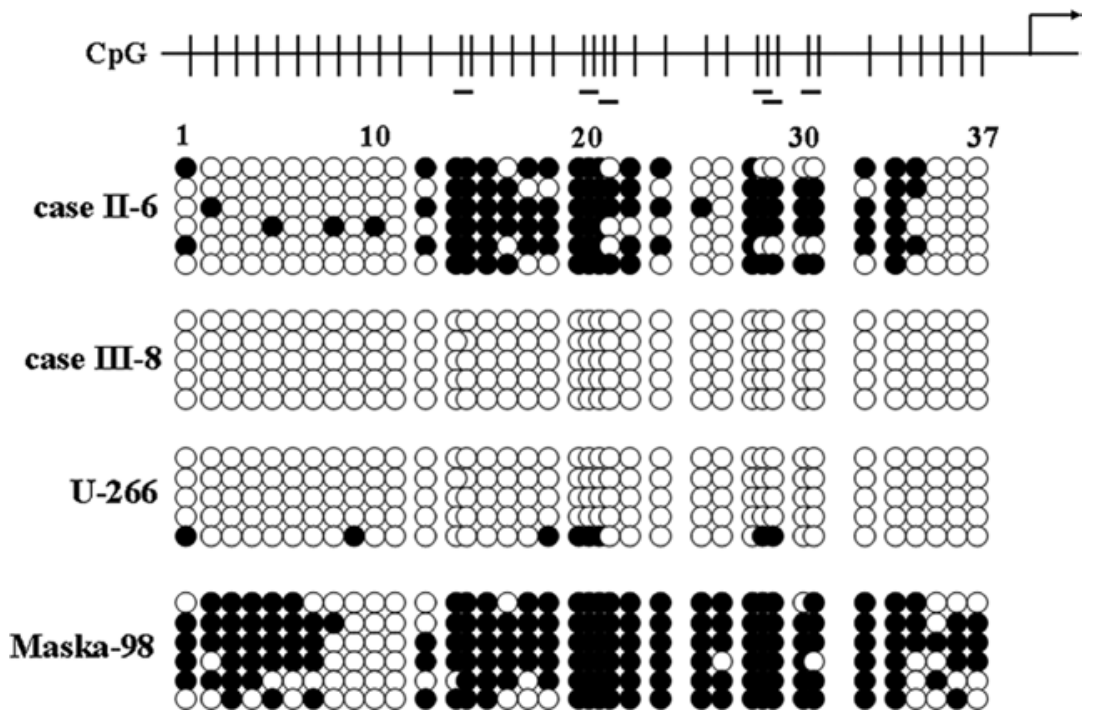

Figure 2. Methylation patterns of individual bisulfite-sequenced clones of the BMP6 promoter in MM cases and MM cell lines. Genomic DNA was subjected to sodium bisulfite conversion, PCR amplification, cloning, and cycle sequencing. Five to six clones from each sample were bisulfite-sequenced to obtain a representative sampling of methylation patterns. Schematic depiction of the $\mathrm{CpG}$ islands in the BMP6 promoter region is shown on top. The $37 \mathrm{CpG}$ sites analyzed are indicated by vertical bars and numbered from left to right. The translation start site is shown by a horizontal arrow. BstUI sites are underlined. Methylated and unmethylated cytosines are shown by closed and open circles, respectively.

A

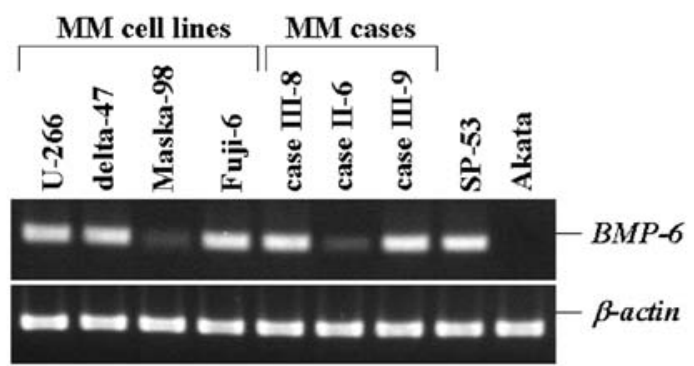

B

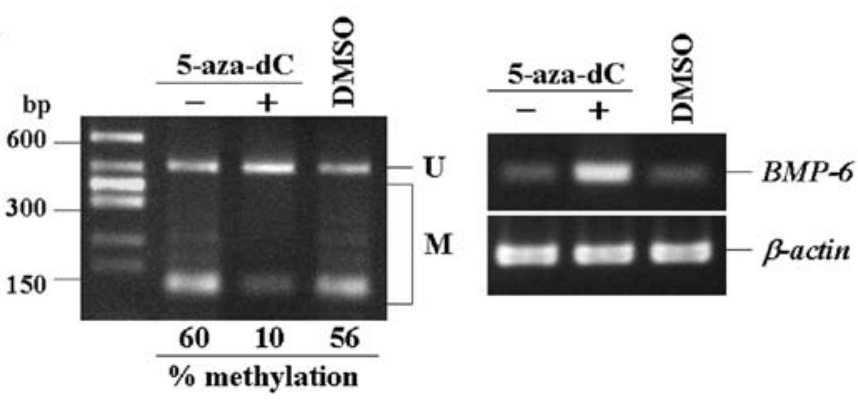

Figure 3. Analysis of BMP6 expression. (A) Representative results of RT-PCR analysis for expression of $B M P 6 \mathrm{mRNA}$ in MM cell lines and MM cases. Samples lacking BMP6 methylation (U-266, delta-47, Fuji-6, case III-8, and case III-9) expressed BMP6 mRNAs, whereas samples with $B M P 6$ methylation (Maska-98 and case II-6) expressed little BMP6 mRNA. $\beta$-actin was used as a control for cDNA integrity and PCR reactions. BMP6 methylation-negative SP-53 with BMP6 mRNA expression and BMP6 methylation-positive Akata cells without BMP6 expression are included as controls. (B) Demethylation of $B M P 6$ promoter reverses transcriptional silencing. COBRA for BMP6 promoter methylation in Maska-98 cells that were incubated in the presence (+) or absence (-) of 5-aza-dC, showing partial demethylation in 5-aza-dC-treated cells (B, left panel). The mock (DMSO, solvent for 5-aza-dC) treatment did not affect the methylation status. Restriction enzyme-undigested and -digested bands were semiquantitated by densitometry, and the calculated percentage of DNA methylation is indicated below each lane. Molecular size marker ( $\phi$ X174/HincII-cut DNA) is shown on the left. U, unmethylated fragment; M, methylated fragment. RT-PCR analysis showing methylation-dependent restoration of BMP6 transcripts (B, right panel). $\beta$-actin was used as a control for cDNA integrity and PCR reactions.

respectively. In the COBRA study, the proportion of methylated (M) vs. unmethylated (U) products (digested vs. undigested bands) was semiquantitated using a densitometer to determine the density of methylation and to compare the percent methylation before and after 5 -aza-dC treatment. The relative percent methylation was calculated as follows: $\mathrm{M} /(\mathrm{M}+\mathrm{U}) \times 100(25)$.
As shown in Fig. 3B, Maska-98 cells showed methylation of the $B M P 6$ promoter, but treatment with 5-aza-dC led to partial demethylation. The mock (DMSO)-treatment did not affect the methylation status. In parallel with the demethylation, there was re-expression of $B M P 6$ transcripts, implying that methylation is associated with transcriptional silencing. 


\section{Discussion}

This study investigated the methylation status of the $B M P 6$ promoter in various types of plasma cell proliferative disorders. While BMP6 methylation was not detected in any samples from MGUS, intramedullary MM, PCL or solitary plasmacytoma, MEP consistently carried the methylated BMP6 promoter, as shown in the case studies at both diagnosis and relapse and in cell line studies. Among the plasma cell malignancies, there are two particularly aggressive forms of PCL and MEP that have a very poor prognosis. Compared with intramedullary MM, organ invasion is common in PCL, while soft tissue tumors involving head, neck and skin are common in MEP (2). MEP can be present at the time of initial diagnosis of MM or develop during the course of disease progression. A noteworthy characteristic of MEP is the elevated serum LDH (2,28-32). Several studies have demonstrated that elevation of LDH levels is associated with the presence of extramedullary disease, an unusually aggressive course and short survival in MM patients $(2,28-32)$. It has been proposed that the prognostic potential of the International MM Staging System (ISS) could be improved by addition of an item for high serum LDH (33-37). In fact, our findings showed that the BMP6 methylation-positive MEP patient samples and cell line expressed extremely high levels of serum LDH, while other types of pretreated MM without $B M P 6$ methylation exhibited normal levels of LDH. Thus, BMP6 methylation together with elevated LDH could be a molecular marker of MEP and a predictor of outcome for aggressive MEP.

We showed a loss of BMP6 expression in BMP6 promoter methylation-positive samples. This transcriptional repression was reversible by treatment with the demethylating agent 5 -aza- $\mathrm{dC}$, suggesting that the methylation is responsible for the transcriptional silencing. In the realm of hematological malignancy, we recently reported that $B M P 6$ promoter methylation and its resultant loss of $B M P 6$ expression were also found more often in aggressive types of malignant lymphomas and leukemias $(23,24)$. Considering that we observed a trend toward BMP6 promoter methylation in aggressive MEP, this methylation appears to be a common phenomenon in such 'high-grade lymphoma-like myeloma'. The present study is the first to implicate in a subset of MMs the methylation and epigenetic inactivation of the BMP family.

In recent years, there has been considerable interest in the role of BMPs in tumorigenesis. As with TGF- $\beta$, it is thought that functional impairment by genetic alteration or epigenetic inactivation of genes involved in the BMP pathway is associated with tumorigenesis and disease progression in various types of malignancies (10). To date, more than 20 BMPs have been characterized and are subdivided, based on amino acid homology, into several classes such as the BMP2/4 group and the BMP5/6/7/8 group (38). As for biological actions of BMPs on myeloma cells, several studies showed roles for BMP2, BMP4, BMP5, BMP6, and BMP7 in inhibition of cell proliferation and induction of apoptosis (17-21). Of these BMPs, BMP6 is the only BMP expressed by normal and subsets of malignant plasma cells (21). Recently, Seckinger et al demonstrated that BMP6 expression is significantly lower in proliferating myeloma cells and plasmablasts, and that BMP6 blocks not only proliferation of myeloma cells, but also inhibits angiogenesis (21). High BMP6 expression was shown to be a favorable prognostic factor independent of conventional prognostic factors; i.e., ISS stage and serum $\beta_{2}$-microglobulin (21). Therefore, BMP6 is now considered as a putative tumor suppressor in MM. Thus, it is logical to assume that maintenance of BMP6 expression may exert antiproliferative effects on myeloma cells, and that the cells of advanced stages of MM would be expected to lose BMP6 expression. During tumor progression, the epigenetic loss of BMP6 expression may be associated with the promotion of myeloma cell proliferation. It is known that despite producing excess amounts of endogenous TGF- $\beta$, myeloma cells are resistant to TGF- $\beta$-mediated inhibition of cell growth and induction of apoptosis (39). Recently, de Carvalho et al reported a loss of TGF- $\beta$ R 2 on the myeloma cell surface because of gene silencing by methylation, and suggested that this could result in myeloma cell resistance to the antiproliferative effects of TGF- $\beta$ (40). By analogy with TGF- $\beta$, it seems plausible that the suppression of autocrine production of endogenous BMP6 by aberrant methylation in myeloma calls could repress their own BMP6 antioncogenic pathway, which could be at least one contributing factor in disease progression. A deeper understanding of the BMP6 signaling pathways will clarify the relevance of BMP6 to MM.

Overall, the present study implies that $B M P 6$ promoter methylation is not a common event in most MM, but can be found in aggressive MEP. Recent reports noted a significant increase in the incidence of MEP $(2,28)$. As patients with MEP have aggressive disease characterized by resistance to therapy, early relapse, and shorter survival compared with MM patients without extramedullary spread, initiation of high-dose chemotherapy at an early stage is needed (2). The rising incidence of MEP observed in recent years urges research to identify specific genetic and epigenetic factors associated with this unique clinical entity. We trust that our findings shed some light on the pathogenesis of MEP and stimulate further analyses to dissect whether BMP6 promoter methylation defines a subgroup of extramedullary $\mathrm{MM}$, and whether it is a useful molecular marker to predict a poor prognosis and tumor progression in MEP patients who should be considered for early intensive treatment. In addition, the use of hypomethylating agents in combination with highdose chemotherapy as a novel therapeutic strategy for MEP also warrants further investigation.

\section{Acknowledgements}

This study was supported by a Grant-in-Aid for Scientific Research from the Japanese Ministry of Education, Culture, Sports, Science and Technology (23591391 to M.D.), and in part by the Kochi University President's Discretionary Grant (to M.D.).

\section{References}

1. Palumbo A and Anderson K: Multiple myeloma. N Engl J Med 364: 1046-1060, 2011.

2. Sher T, Miller KC, Deeb G, Lee K and Chanan-Khan A: Plasma cell leukemia and other aggressive plasma cell malignancies. $\mathrm{Br}$ J Haematol 150: 418-427, 2010.

3. Bergsagel PL and Kuehl WM: Molecular pathogenesis and a consequent classification of multiple myeloma. J Clin Oncol 23: 6333-6338, 2005.

4. Munshi NC and Avet-Loiseau H: Genomics in multiple myeloma. Clin Cancer Res 17: 1234-1242, 2011. 
5. Galm O, Wilop S, Reichelt J, Jost E, Gehbauer G, Herman JG and Osieka R: DNA methylation changes in multiple myeloma. Leukemia 18: 1687-1692, 2004.

6. Ng MH, Chung YF, Lo KW, Wickham NW, Lee JC and Huang DP: Frequent hypermethylation of p16 and p15 genes in multiple myeloma. Blood 89: 2500-2506, 1997.

7. Walker BA, Wardell CP, Chiecchio L, Smith EM, Boyd KD, Neri A, Davies FE, Ross FM and Morgan GJ: Aberrant global methylation patterns affect the molecular pathogenesis and prognosis of multiple myeloma. Blood 117: 553-562, 2011.

8. Miyazono K, Maeda S and Imamura T: BMP receptor signaling: transcriptional targets, regulation of signals, and signaling crosstalk. Cytokine Growth Factor Rev 16: 251-263, 2005.

9. Bhatia M, Bonnet D, Wu D, Murdoch B, Wrana J, Gallacher L and Dick JE: Bone morphogenetic proteins regulate the developmental program of human hematopoietic stem cells. J Exp Med 189: 1139-1148, 1999.

10. Blanco CM, Bolós FV, Medina VV, Aparicio GG, Diaz PS and Grande PE: Biology of BMP signalling and cancer. Clin Transl Oncol 11: 126-137, 2009.

11. Kodach LL, Wiercinska E, de Miranda NF, Bleuming SA, Musler AR, Peppelenbosch MP, Dekker E, van den Brink GR, van Noesel CJ, Morreau H, Hommes DW, Ten Dijke P, Offerhaus GJ and Hardwick JC: The bone morphogenetic protein pathway is inactivated in the majority of sporadic colorectal cancers. Gastroenterology 134: 1332-1341, 2008.

12. Horvath LG, Henshall SM, Kench JG, Turner JJ, Golovsky D, Brenner PC, O'Neill GF, Kooner R, Stricker PD, Grygiel JJ and Sutherland RL: Loss of BMP2, Smad8, and Smad4 expression in prostate cancer progression. Prostate 59: 234-242, 2004.

13. Wen XZ, Akiyama Y, Baylin SB and Yuasa Y: Frequent epigenetic silencing of the bone morphogenetic protein 2 gene through methylation in gastric carcinomas. Oncogene 25: 2666-2673, 2006.

14. Dai Z, Lakshmanan RR, Zhu WG, Smiraglia DJ, Rush LJ, Frühwald MC, Brena RM, Li B, Wright FA, Ross P, Otterson GA and Plass C: Global methylation profiling of lung cancer identifies novel methylated genes. Neoplasia 3: 314-323, 2001.

15. Dai Z, Popkie AP, Zhu WG, Timmers CD, Raval A, TannehillGregg S, Morrison CD, Auer H, Kratzke RA, Niehans G, Amatschek S, Sommergruber W, Leone GW, Rosol T, Otterson GA and Plass C: Bone morphogenetic protein 3B silencing in non-small cell lung cancer. Oncogene 23: 3521-3529, 2004

16. Kraunz KS, Nelson HH, Liu M, Wiencke JK and Kelsey KT: Interaction between the bone morphogenetic proteins and Ras/ MAP-kinase signalling pathways in lung cancer. Br J Cancer 93: 949-952, 2005.

17. Ro TB, Holt RU, Brenne AT, Hjorth-Hansen H, Waage A, Hjertner O, Sundan A and Borset M: Bone morphogenetic protein-5, -6 and -7 inhibit growth and induce apoptosis in human myeloma cells. Oncogene 23: 3024-3032, 2004.

18. Kawamura C, Kizaki M, Yamato K, Uchida H, Fukuchi Y, Hattori Y, Koseki T, Nishihara T and Ikeda Y: Bone morphogenetic protein-2 induces apoptosis in human myeloma cells with modulation of STAT3. Blood 96: 2005-2011, 2000.

19. Hjertner Ö, Hjorth-Hansen H, Börset M, Seidel C, Waage A and Sundan A: Bone morphogenetic protein-4 inhibits proliferation and induces apoptois of multiple myeloma cells. Blood 97: 516-522, 2001

20. Fukuda N, Saitoh M, Kobayashi N and Miyazono K: Execution of BMP-4-induced apoptosis by p53-dependent ER dysfunction in myeloma and B-cell hybridoma cells. Oncogene 25: 3509-3517, 2006.

21. Seckinger A, Meissner T, Moreaux J, Goldschmidt H, Fuhler GM, Benner A, Hundemer M, Rème T, Shaughnessy JD Jr, Barlogie B, Bertsch U, Hillengass J, Ho AD, Pantesco V, Jauch A, De Vos J, Rossi JF, Möhler T, Klein B and Hose D: Bone morphogenic protein 6: a member of a novel class of prognostic factors expressed by normal and malignant plasma cells inhibiting proliferation and angiogenesis. Oncogene 28: 3866-3879, 2009.

22. Tamada H, Kitazawa R, Gohji K, Kamidono S, Maeda S and Kitazawa S: Molecular cloning and analysis of the 5'-flanking region of the human bone morphogenetic protein-6 (BMP-6). Biochim Biophys Acta 1395: 247-251, 1998.

23. Daibata M, Nemoto Y, Bandobashi K, Kotani N, Kuroda M, Tsuchiya M, Okuda H, Takakuwa T, Imai S, Shuin T and Taguchi H: Promoter hypermethylation of the bone morphogenetic protein- 6 gene in malignant lymphoma. Clin Cancer Res 13: 3528-3535, 2007
24. Taniguchi A, Nemoto Y, Yokoyama A, Kotani N, Imai S, Shuin T and Daibata M: Promoter methylation of the bone morphogenetic protein-6 gene in association with adult T-cell leukemia. Int J Cancer 123: 1824-1831, 2008

25. Xiong $\mathrm{Z}$ and Laird PW: COBRA: a sensitive and quantitative DNA methylation assay. Nucleic Acids Res 25: 2532-2534, 1997.

26. Drexler HG: Myeloma and plasma cell leukemia B-cell lines. In: Guide to Leukemia-Lymphoma Cell Lines. Drexler HG (ed.) eBook CD, Braunschweig, pp281-357, 2005.

27. Hatakeyama N, Daibata M, Nemoto Y, Ohtsuki Y and Taguchi H: Lactate dehydrogenase production and release in a newly established human myeloma cell line. Am J Hematol 66: 267-273, 2001.

28. Varettoni M, Corso A, Pica G, Mangiacavalli S, Pascutto C and Lazzarino M: Incidence, presenting features and outocome of extramedullary disease in multiple myeloma: a longitudinal study on 1003 consecutive patients. Ann Oncol 21: 325-330, 2010.

29. Dimopoulos MA, Barlogie B, Smith TL and Alexanian R: High serum lactate dehydrogenase level as a marker for drug resistance and short survival in multiple myeloma. Ann Intern Med 115: 931-935, 1991.

30. Barlogie B, Smallwood L, Smith T and Alexanian R: High serum levels of lactic dehydrogenase identify a high-grade lymphomalike myeloma. Ann Intern Med 110: 521-525, 1989.

31. Sanal SM, Yaylaci M, Mangold KA and Pantazis CG: Extensive extramedullary disease in myeloma: an uncommon variant with features of poor prognosis and dedifferentiation. Cancer 77: 1298-1302, 1996.

32. Allen SL and Coleman M: Aggressive phase multiple myeloma: a terminal anaplastic transformation resembling high-grade lymphoma. Cancer Invest 8: 417-424, 1990.

33. Terpos E, Katodritou E, Roussou M, Pouli A, Michalis E, Delimpasi S, Parcharidou A, Kartasis Z, Zomas A, Symeonidis A, Viniou NA, Anagnostopoulos N, Economopoulos T, Zervas K and Dimopoulos MA; Greek Myeloma Study Group: High serum lactate dehydrogenase adds prognostic value to the international myeloma staging system even in the era of novel agents. Eur J Haematol 85: 114-119, 2010

34. Kyrtsonis MC, Maltezas D, Tzenou T, Koulieris E and Bradwell AR: Staging systems and prognostic factors as a guide to therapeutic decisions in multiple myeloma. Semin Hematol 46: 110-117, 2009.

35. García-Sanz R, González-Fraile MI, Mateo G, Hernández JM, López-Berges MC, de las Heras N, Fernández-Calvo J, Ortega F, Portero JA, Bárez A, Galende J, Orfão A and San Miguel JF: Proliferative activity of plasma cells is the most relevant prognostic factor in elderly multiple myeloma patients. Int J Cancer 112: 884-889, 2004.

36. Munshi NC, Anderson KC, Bergsagel PL, Shaughnessy J, Palumbo A, Durie B, Fonseca R, Stewart AK, Harousseau JL, Dimopoulos M, Jagannath S, Hajek R, Sezer O, Kyle R, Sonneveld P, Cavo M, Rajkumar SV, San Miguel J, Crowley J and Avet-Loiseau H; International Myeloma Workshop Consensus Panel 2: Consensus recommendations for risk stratification in multiple myeloma: report of the International Myeloma Workshop Consensus Panel 2. Blood 117: 4696-4700, 2011.

37. Dimopoulos M, Kyle R, Fermand JP, Rajkumar SV, San Miguel J, Chanan-Khan A, Ludwig H, Joshua D, Mehta J, Gertz M, AvetLoiseau H, Beksaç M, Anderson KC, Moreau P, Singhal S, Goldschmidt H, Boccadoro M, Kumar S, Giralt S, Munshi NC and Jagannath S; International Myeloma Workshop Consensus Panel 3: Consensus recommendations for standard investigative workup: report of the International Myeloma Workshop Consensus Panel 3. Blood 117: 4701-4705, 2011.

38. Kawabata M, Imamura $\mathrm{T}$ and Miyazono K: Signal transduction by bone morphogenetic proeins. Cytokine Growth Factor Rev 9: 49-61, 1998.

39. Amoroso SR, Huang N, Roberts AB, Potter M and Letterio JJ: Consistent loss of functional transforming growth factor beta receptor expression in murine plasmacy toma. Proc Natl Acad Sci USA 95: 189-194, 1998.

40. de Carvalho F, Colleoni GWB, Almedia MSS, Carvalho AL and Vettore AL: TGF $\beta R 2$ aberrant methylation is a potential prognostic marker and therapeutic target in multiple myeloma. Int $\mathbf{J}$ Cancer 125: 1985-1991, 2009. 